\title{
AN APPLICATION OF THE RELATIVE WARPS ANALYSIS TO PROBLEMS IN HUMAN PALEONTOLOGY - WITH NOTES ON RAW DATA QUALITY
}

\author{
MARTIN FRIEß \\ Laboratoire d'Anthropologie, Université Bordeaux 1, Talence, France \\ American Museum of Natural History, Division of Paleontology, 10024 New York, NY, USA \\ e-mail: mfriess@amnh.org \\ (Accepted February 17, 2003)
}

\begin{abstract}
This study investigates the use of geometric morphometrics as well as methodological aspects specifically related to its application in paleoanthropology. Based on lateral photographs taken from a fossil sample of 58 specimens, a relative warps analysis was computed in order to assess the variation of cranial shape among various hominin groups. The fossil sample represents Middle and Late Pleistocene populations commonly assigned to $H$. erectus, $H$. neanderthalensis, archaic $H$. sapiens as well as anatomically modern $H$. sapiens. The preliminary results indicate that several fossil skulls considered as belonging to archaic $H$. sapiens have a distinct shape compared to modern humans. The results suggest that these hominins are not as closely related to modern humans as previously thought. Instead, their morphometric affinities suggest that they are as distinct from modern humans as are the Neandertals. Methodological aspects, such as raw data accuracy and the use of type 2 and 3 landmarks that are directly related to this type of quantitative analysis and that potentially affect their results, are discussed.
\end{abstract}

Keywords: cranial shape, deficient landmarks, geometric morphometrics, paleoanthropology, photographic distortion.

\section{INTRODUCTION}

Questions related to modern human origins have largely dominated the paleoanthropological output of the last decade (Nitecki and Nitecki, 1994; Wood, 1994). Despite ongoing discussions, the idea of an African origin of modern humans appears to emerge as a general consensus, although certain details about this process remain open for debate. For instance, several authors claim a single African origin of modern humans in the sense of a speciation event (Cann et al., 1987; Stringer, 1994; Chaline, 1998), while Bräuer (1984; Bräuer et al., 1997) suggested a model of an African origin with more gradual elements. According to this model, modern humans evolved around 200,000 to 100,000 years bp (before present) in South and East Africa from Homo erectus-like, archaic populations that are represented by specimens like Ndutu, Kabwe, Omo 2, Eliye Springs, Singa and others and referred to 'archaic Homo sapiens'. Around 100,000 years bp, specimens like Omo 1 (Ethiopia) as well as Skhul and Qafzeh (Israel) are thought to represent the earliest anatomically modern human forms. This series of fossils is referred to as the African transition (from archaic to modern humans). In opposition to the multiregional model (Wolpoff et al., 1984), which will not be addressed here, both African scenarios consider that Neandertal populations from Europe and the Near East were marginal to or even excluded from the origin and dispersal of modern humans.

The purpose of this paper is to investigate the variation of cranial size and shape in Middle and Late Pleistocene fossil hominins from Europe, Asia and Africa using geometric morphometrics. Although uncertainties often remain regarding the absolute age of fossil remains, the sample of this study covers a time range between ca. 1 million years and 10,000 years bp. Within the background of the modern human origins debate, the initial idea of this study is to test the hypothesis of a gradual evolution from early archaic Homo sapiens to anatomically modern humans in Africa, the model proposed by Bräuer (1984; Bräuer et al., 1997). Here, in addition to reporting results and discussing their phylogenetic implications, we will emphasize a few methodological 
issues that in our view are often associated with shape analysis of fossil hominins.

The morphometric analysis of biological shapes is a common approach to assessing affinities of organisms in general. According to Rohlf and Marcus (1993), geometric morphometric techniques are particularly powerful in that they combine the usual multivariate statistics with the geometry of the object and therefore graphically illustrate shape differences. Its application in paleoanthropology should therefore contribute to the quantification of evolutionary trends among fossil populations.

\section{MATERIAL AND METHODS}

In order to study the variation of cranial shape during the end of the Pleistocene, raw data were collected from 58 fossils, dating from the Middle Pleistocene at or slightly below 1 million years (Homo erectus) to the Late Pleistocene, about 10,000 bp (European and Near Eastern Upper and Epipaleolithic crania, Table 1). During this relatively long time range, non-modern hominin forms existed throughout the Old World, as is witnessed by Neandertals in Europe, and Homo heidelbergensis or archaic Homo sapiens in Africa and Europe. It is also the time period, during which the earliest modern Humans are believed to have appeared, somewhere by the end of the Middle Pleistocene, beginning of the Late Pleistocene (dated to 125,000 bp).

\section{SHAPE ANALYSIS USING GEOMETRIC MORPHOMETRICS}

Bookstein (1991) introduced a series of techniques for the statistical analysis of shape variation, now commonly referred to as geometric morphometrics. Within this framework, a biological shape is assessed through homologous landmarks that summarize the geometry or form of the organism under study. The landmark configuration of each specimen is then normalized for translation, rotation and scaled to a common size, so that the remaining differences between individual or mean shapes are differences in shape only. This is achieved by Procrustes superimposition, a least squares type of registration method that minimizes the distance between pairs of homologous landmarks. Once landmark configurations are Procrustes aligned, shape variables can be extracted either by a GPA (Generalized Procrustes Analysis, Rohlf, 2000) or, as in this paper, through a relative warps analysis (Bookstein, 1991). These shape

Table 1. Fossil specimens, and their time range, used in tihis study.

\begin{tabular}{|c|c|c|c|c|}
\hline Group & Relative age & $\begin{array}{c}\text { General } \\
\text { morphology }\end{array}$ & $\mathrm{N}$ & Original specimens and casts $(*)$ \\
\hline $\begin{array}{l}\text { Asian H. erectus } \\
(\leq 1 \mathrm{MY})\end{array}$ & Middle & \multirow{3}{*}{ 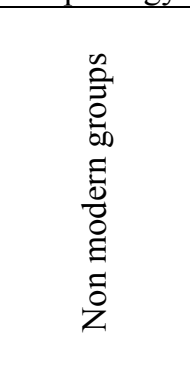 } & 1 & Sangiran 2 \\
\hline $\begin{array}{l}\text { Archaic Homo sapiens / } \\
\text { H. heidelbergensis } \\
(90,000-400,000 \mathrm{BP})\end{array}$ & \multirow{3}{*}{ 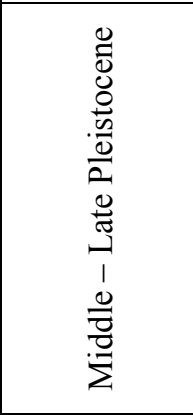 } & & 6 & Eliye Springs*, Kabwe, LH 18*, Ndutu*, Omo 2*, Singa \\
\hline $\begin{array}{l}\text { H. neanderthalensis } \\
(34,000-170,000 \mathrm{BP})\end{array}$ & & & 12 & $\begin{array}{l}\text { Amud 1, La Chapelle-aux-Saints, La Ferrassie } 1 \text { Forbes' } \\
\text { Quarry, Guattari 1, Neandertal, La Quina H5, } \\
\text { Saccopastore 1+2, } \\
\text { Saint-Césaire, Shanidar 1*, Tabun C }\end{array}$ \\
\hline $\begin{array}{l}\text { Earliest anatomically moder } \\
\text { Homo sapiens } \\
(90,000-130,000 \mathrm{BP})\end{array}$ & & \multirow{3}{*}{ 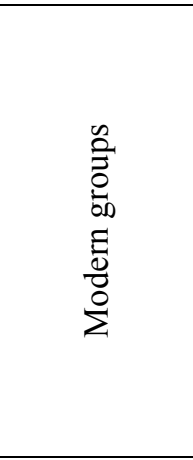 } & 6 & Omo 1, Qafzeh 6+9, Skhul 4+5+9 \\
\hline $\begin{array}{l}\text { Early Upper Paleolithic } \\
(35,000-20,000 \mathrm{BP})\end{array}$ & \multirow[b]{2}{*}{ 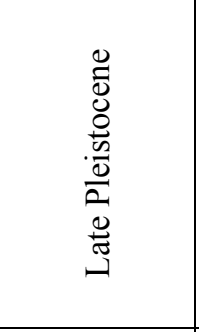 } & & 8 & Abri Pataud; Brno 2; Cro-Magnon 1-3; Mladec 1-3 \\
\hline $\begin{array}{l}\text { Late Upper } \\
\text { Paleolithic/Epipaleolithic } \\
(\leq 20,000 \mathrm{BP})\end{array}$ & & & 25 & $\begin{array}{l}\text { Arene Candide 1, 4, 5, "Prince", n. num; Avelines Hole; } \\
\text { Barma Grande 2, 3: Cheddar; Nahal Ein Gev 1; Erq el- } \\
\text { Ahmar H2; Fallah 16, 23; Hayonim 4; Langwith Cave; } \\
\text { Le Bichon; } \\
\text { Mallaha 37; Oberkassel 1, 2; Ohalo II; Rond du Barry; } \\
\text { San Teodoro 3; Uzzo IVa, b; Veyrier } 1\end{array}$ \\
\hline Total & & & 58 & \\
\hline
\end{tabular}


variables can further be used as input to standard uniand multivariate analyses and the observed variation and mean differences can be visually represented in the picture plane in which the raw data (i.e., landmarks) were originally recorded. Besides the improved statistical parameterization of size and shape, the approach also strongly enhances the biological interpretation of statistical observations.

The relative warps analysis (Bookstein, 1991) was performed using the software tpsRelw (Rohlf, 1997). Relative warps analysis corresponds to a Principal Components analysis of the covariance matrix of the partial warp scores, which are different scales of a thin-plate spline transformation of landmarks. The thinplate spline is a smooth interpolation function that computes and visualizes transformations of Cartesian Coordinates in a way similar to D'Arcy Thompson's transformation grids (Thompson, 1917). A rectangular grid is projected over Procrustes aligned landmark configurations and the bending of the grid visually depicts the difference in landmark locations between 2 configurations. The Thin-plate spline uses the analogy of an infinitely thin metal sheet that is bent so that points on it move from their original position to a defined target position. The closer two positions are, the more bending energy is required, whereas large scale transformations require less energy. Shape differences between any two landmark configurations are visualized as landmark displacement, while the changes in the space between landmarks are interpolated. Every specimen of a sample is compared to the mean (or consensus) configuration of the sample, and shape changes along any axis of interest (here, the relative warps, see Figs. 4-7) are visualized as deviations from the mean configuration. Given its similarity with a Principal Components Analysis, relative warps are a tool for exploring within-sample variation serving to reduce the total variation to a smaller number of independent dimensions. Typically, the first few components or relative warps summarize most of the variation of a sample.

Subsequently, size allometry (i.e. shape change as a function of size) was estimated by calculating correlations between relative warp scores and centroid size. Centroid size, the square root of the sum of the squared distances between all homologous landmarks and the center of gravity of the landmarks, is commonly used as general size measure in geometric morphometrics and was computed with GRF-ND (Slice, 1994). For all statistics, except the relative warps, a standard package of statistical software was used (Statistica version 5.1, StatSoft France, 1998). The landmarks were all collected in the lateral view and correspond to six different data sets (Frieß, 1999). This procedure takes into account specific variation of fossil humans, and is the best way to cope with their generally poor state of preservation, since estimating missing values remains critical. Furthermore, some of the landmarks included are bilateral points, and by default they were taken on one side only. For modern humans, this assumes symmetry which is known to hardly apply to any living organism having a symmetry axis. However, given that in fossils both sides are virtually never preserved, it was impossible to address the question of asymmetry in this study.
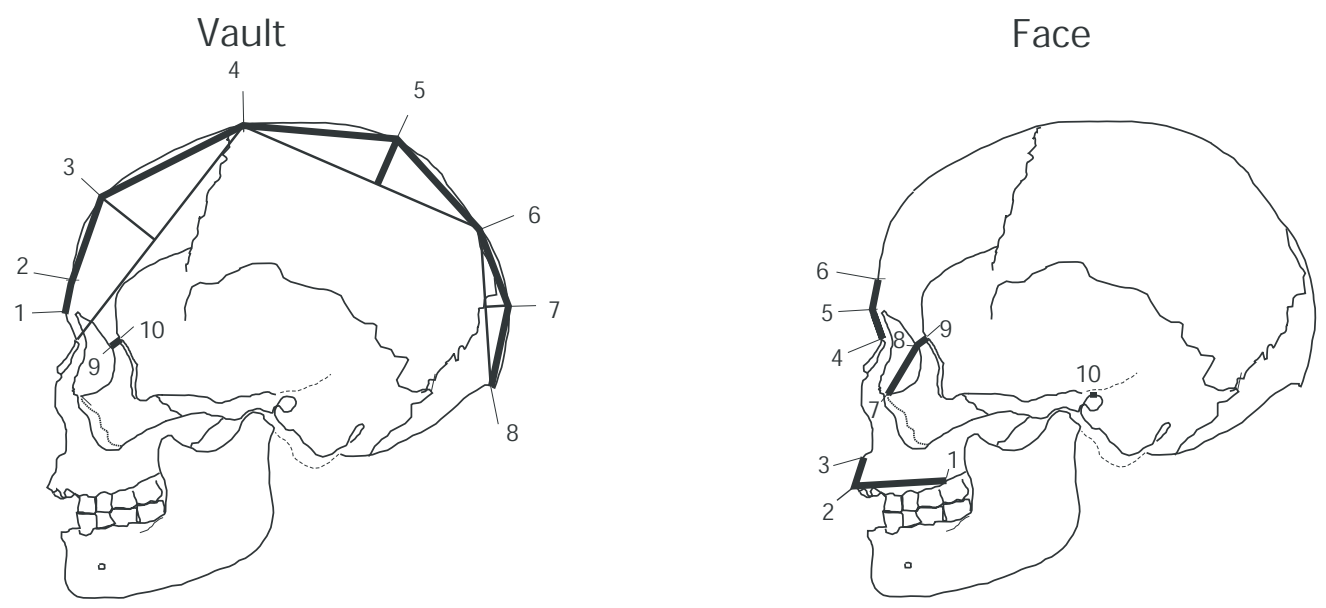

Fig. 1. Schematic illustration of the landmarks used for this study. These landmarks correspond to standard craniometric points except nos. 3, 5 and 7 in the vault configuration, which are so-called deficient landmarks. 
Most of the raw data were recorded from original specimens, but six original specimens were not available and had to be replaced with casts. Based on lateral outlines of these crania, op to 19 landmarks were defined and digitized using a PC and the tpsdig software (Rohlf, 1996) (type 1 to 3, see Fig. 1). A type 1 landmark is a point that is unambiguously defined (typically by the juxtaposition of tissues) and therefore can be claimed to be homologous. A type 2 landmark commonly is a curvature maximum, its homology is therefore based on the geometry rather than the anatomy. Finally, a type 3 landmark is an extremal landmark, e.g. one end of a diameter etc. It is considered to be a deficient landmark, because its coordinates depend on some kind of orientation or construction. And therefore considered to be of limited use in geometric morphometrics (Bookstein, 1991).

\section{RAW DATA ACCURACY}

As was emphasized in the introduction, an additional goal of this paper is to raise a few methodological questions with regard to the use of 2D representations of 3D objects (i.e., pictures of skulls) as well as previous applications of geometric morphometrics in paleoanthropology (Yaroch, 1996).

As far as the use of 2D geometric morphometrics is concerned, one possible way of obtaining raw data for such analyses is by using drawings or photographs commonly used to document the fossil record. Photographs, however, may not always be suitable for metric comparisons because of the well known principle of optical distortion (Fig. 2, cf. Jacobshagen et al., 1988). Any optical lens leads to distortion of the absolute and relative dimensions of a spherical object like a skull. The outer edge of the sphere will be invisible in a central projection, affecting absolute dimensions. Secondly, objects that are closer to the focal point will appear relatively bigger than they are compared to portions that are further away, affecting thereby the proportions of the object. In practical terms this means that taking a picture of a human cranium with a distance of 1 meter, not uncommon for published high-quality illustrations, results in a distortion of about $7.5 \%$, which is hardly acceptable. These distortions can be mostly avoided by stereophotographic techniques. Alternatively, if no 3D devices are available, increasing the distance between the camera and the object can significantly reduce the photographic error. In order to obtain accurate cranial outlines in 2D, a simple standardized photogrammetric protocol with a maximal distance of 6.5 meters to the specimen was used. The specimen was positioned exactly in the optical axis of the camera, and its symmetry axis was aligned perpendicular to the optical axis. Camera and center of volume of the specimen were at level along 2 axes, the third being defined by the distance between them. This distance varied between $5 \mathrm{~m}$ and $6.5 \mathrm{~m}$ and was merely dependent on local settings, knowing that the optical distortion at $5 \mathrm{~m}$ and more is below $2 \%$. The mean deviation between standard measurements taken on the crania and the same set of measurements taken on the photographs was found to be less than a millimeter (Frieß, 1997), which is considered as an acceptable error in anthropometry. These considerations allow us to hypothesize that raw data that are derived from pictures and taken without the necessary respect of basic photogrammetry are less reliable. The following example (Fig. 3) which refers to a study based on published photographs of fossil hominins (Yaroch, 1996) may serve to illustrate this issue. This figure shows the thin-plate spline from a standardized picture (Frieß, 1999) of a Neandertal cranium (Amud 1) to a published picture of the same specimen (Suzuki and Takai, 1970). In this specific case the optical distortion tends to reduce certain traits that are usually common in Neandertals, such as (Fig. 3):

- the alveolar prognathism, i.e., projecting upper jaw,

- the strong supraorbital torus (brow ridges),

- the relatively flat vault, especially in the parietal region and

- the occipitalbun in the back of the skull.

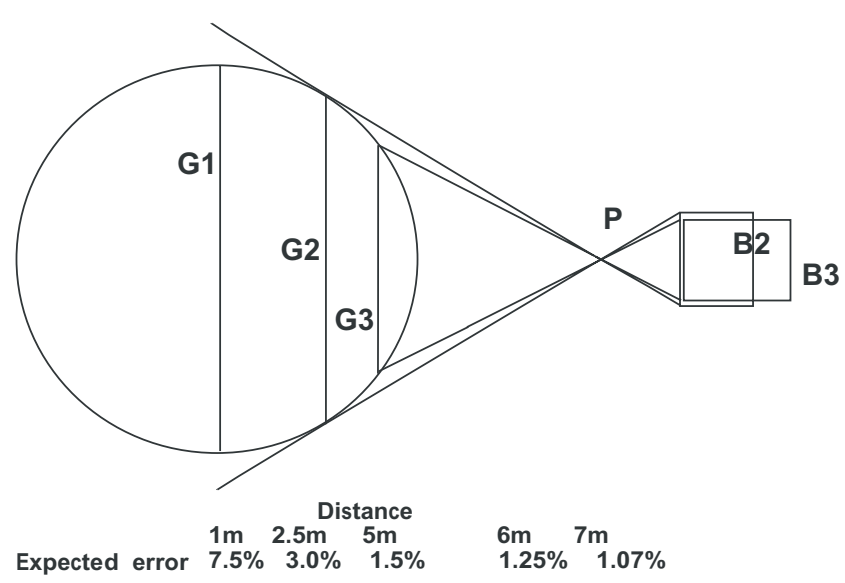

Fig. 2. (after Jacobshagen et al. 1988): Optical distortion due to a central projection affects measurement accuracy at two levels: The maximum diameter of a given object (dimension G1) is only partly visible to the camera on the right, and therefore erroneously measured smaller than in reality (dimension G2). The ratio between any dimension situated between the maximum diameter and the camera $(G 3 / G 1)$, is incorrectly reproduced on 
the film (B3/B2). The values for the expected error are based on the dimensions of a human skull

These distortions could then lead to the, in our view erroneous, impression that Neandertals are actually 'less Neandertal-like' than generally thought, simply because their cranial shape was insufficiently reproduced in these pictures (see c.f., Yaroch, 1996 who noted an absence of a clearly distinct Neandertal cranial shape compared to modern humans).

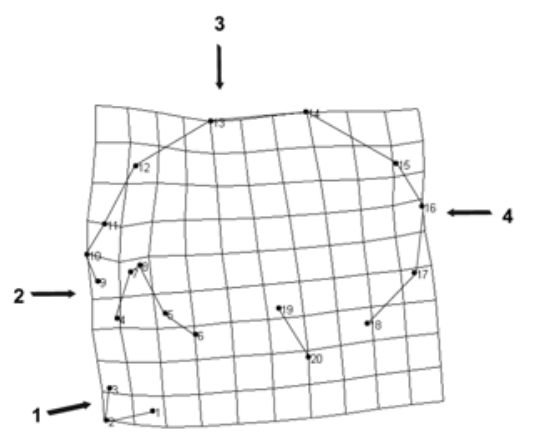

Fig. 3. The thin-plate spline function can be used in order to map differences in the landmark locations of two pictures of the same skull (the Amud 1 Neandertal). The 2 pictures are taken at different distances (a picture published by Suzuki and Takai, 1970, is compared to a standardized picture taken by the author (Frieß, 1999). The distortion affects typical Neandertal features, such as the occipital bun, the midfacial and alveolar prognathism and the flatness of the vault (landmarks as defined in Yaroch 1996).

\section{CRANIOFACIAL SHAPE VARIATION DURING THE MIDDLE AND LATE PLEISTOCENE}

The first analysis is based on 10 landmarks of the vault. The first and second axis of the relative warps analysis account for $60 \%$ of the variation, with the first component explaining $49.1 \%$ (Fig. 4a). This first axis allows for a very clear distinction between two poles: The modern cranial shape, represented by Upper Paleolithic and Epipaleolithic fossils (recovered from Europe and the Near East and dated between 35,000 and 10,000 years) as well as the Middle Paleolithic Skhul/Qafzeh group (Israel, ca. 100,000 years bp); and a non-modern group including Neandertals $(170,000-35,000)$ and archaic Homo sapiens $(400,000-90,000)$. The only $H$. erectus specimen (Sangiran 2) is clearly part of this group. Note that some of the specimens grouped here as archaic Homo sapiens have also been classified as Homo heidelbergensis, and are often seen as ancestors of Neandertals and/or Homo sapiens (Tattersall,
1995; Rightmire, 1996). The second axis separates the Neandertal lineage from the rest of the archaic specimens, although some overlap exists along this second axis.

The main shape difference in the vault that is associated with the relative warps is visualized as landmark displacement using the thin-plate spline function (Fig. 5a). This reveals for the whole nonmodern group along the first axis a flat vault, which is horizontally elongated and exhibits a strong supraorbital torus and a pronounced occipital convexity. The second axis (Fig. 5b) seems to differentiate among the more archaic (non-modern) crania those who show an occipital bun, often considered a Neandertal character, from those who do not exhibit such a bun.

a)

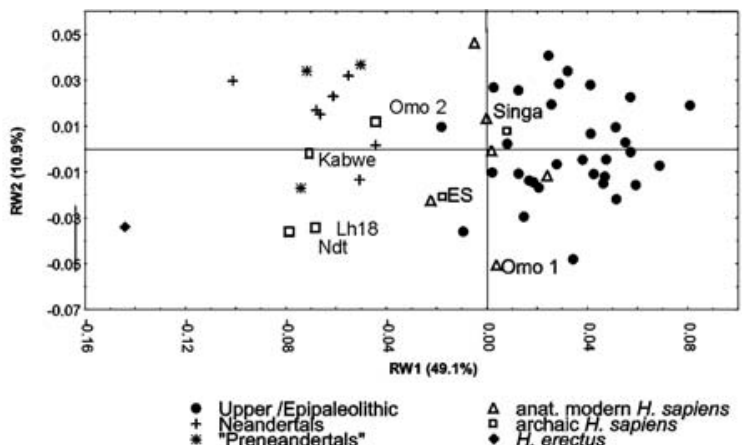

b)

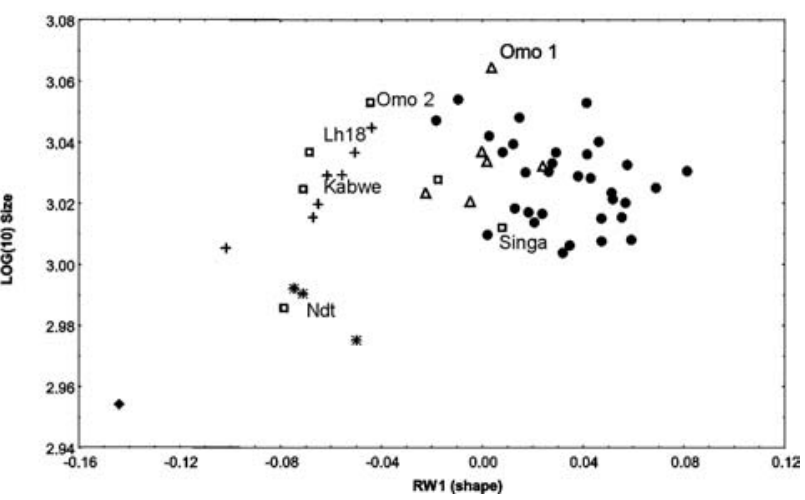

Fig. 4. Relative warps analysis of the vault of Middle and Late Pleistocene hominins. a) individual scores on relative warps 1 and 2 (ES = Eliye Springs, $N d t=N d u t u$, Lh18 = Laetoli Hominid 18), b) biplot of relative warp 1 against centroid size (no significant overall allometry).

Judging from the correlations between these warps and centroid size (Fig. 4b), the first axis appears to depend moderately on size $(r=0.35$, $\mathrm{p}=0.009$ ). Given that significant size differences are only observed between 2 major clusters, modern and non-modern fossils, the observed allometry therefore mainly concerns differences between Homo erectus, Neandertals and archaic Homo sapiens on the one hand and anatomically modern humans on the other. A 
strong correlation $(\mathrm{r}=0.6, \mathrm{p}=0.002)$ among the nonmodern groups was also observed and may reflect the size differences between early and classic Neandertals. No significant correlations $(r=-0.34$, $p>0.05)$ were observed among the fossil crania with modern shape (dating from the Upper Paleolithic and Epipaleolithic).

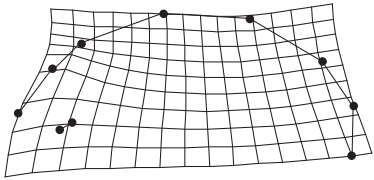

a)

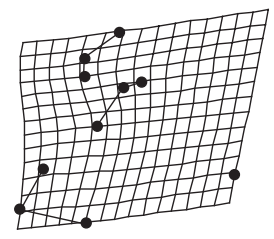

c)

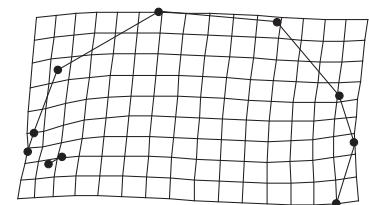

b)

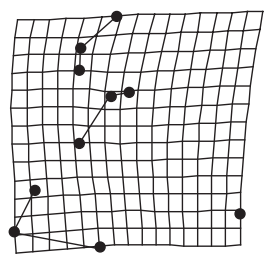

d)
Fig. 5. Shape change associated with the first two relative warps ( $r w$ ), using the thin-plate function for visualization. The grids represent the change associated with a) negative scores on $r w 1$ for the vault b) negative scores on $r w 2$ for the vault c) negative scores on $r w 1$ for the face d) negative scores on $r w 2$ for the face.

As far as facial variation is concerned, the differences between modern humans and more archaic populations are much weaker, as is shown in Fig. 6a. In fact, although archaic faces all cluster together due to negative scores on both first and second relative warps (33 and 17\%), they overlap with clearly modern faces, such as the Natoufian Mallaha 37 or the Skhul/Qafzeh group, which is considered to represent some of the earliest anatomically modern humans. Here, they are grouped closely together with Neandertals, a non-modern form that occupied Europe between 170,000 and 35,000 years ago and that is believed to have disappeared without descendents.

The shape change associated with these axes (Figs. 5c and 5d) confirms for the group of nonmodern faces the presence of a general prognathism (a projecting upper jaw), a strong supraorbital torus (brow ridges) as well as a zygomatic retreat (cheek). Such a facial morphology has been described as typical for Neandertals (Rak, 1986; Trinkaus, 1987). Our data show that fossils of clearly modern vault shape tend to exhibit this supposedly typical Neandertal facial morphology, which leads us to reconsider its status as 'Neandertal-like'. Furthermore, this combination of facial characters is also present in Kabwe, considered by some authors as archaic $H$. sapiens, while some others associate it with $H$. heidelbergensis, a possible ancestor of Neandertals. Our findings support the latter model. The overlap of modern and non-modern facial morphologies can be explained by allometry, as is illustrated in the biplot of relative warp 1 against centroid size. This relation is seen in Fig. 6b, and one can observe that the correlation is very strong $(r=-0.78)$ and highly significant $(p<0.001)$. From this, it can be proposed that some aspects of Neandertal facial morphology are merely a result of allometry (shape change due to size increase), which at the same time could explain the presence of this plesiomorphic (ancestral) trait in clearly modern fossils like the Skhul/Qafzeh group, as these specimens have higher scores for centroid size.

Certain phylogenetic considerations of this study can be emphasized. Comparing the evolution of size and shape among later Pleistocene hominins by performing a relative warps analysis and subsequent allometry study indicates that most of the so-called African transitional specimens (except for Omo 1 and Singa, see below) are very distinct from the modern human cranial shape (represented by Skhul/Qafzeh and the Upper to Epipaleolithic samples) and do not show any trend towards the anatomically modern populations, except for size (Frieß, 1999). In fact, when plotted against generally accepted absolute dates, archaic Homo sapiens was found to exhibit an increase in overall size. Size increase, however, is of less phylogenetic relevance because it is also observed in the Neandertal lineage. Therefore these results do not support a model of gradual evolution of Homo sapiens in Africa. Most of the so-called transitional African hominins appear to retain a generally plesiomorphic craniofacial shape and are as distinct from modern humans as are Neandertals. Conversely, the data are consistent with either a more rapid speciation event during the African later Pleistocene (Stringer, 1994), or with a Near Eastern origin of modern humans (Vandermeersch, 1981; Mann, 1995), as exemplified by the Skhul/Qafzeh hominins. However, support for the former model from this study can only be seen in a fairly limited number of fossils (Omo 1, Singa) and therefore requires further investigation using the approach presented here. Moreover, as far as facial morphology is concerned, essential aspects of Neandertal facial morphology can be considered as widely 
plesiomorphic and dependent on size, rather than a derived character.

a)

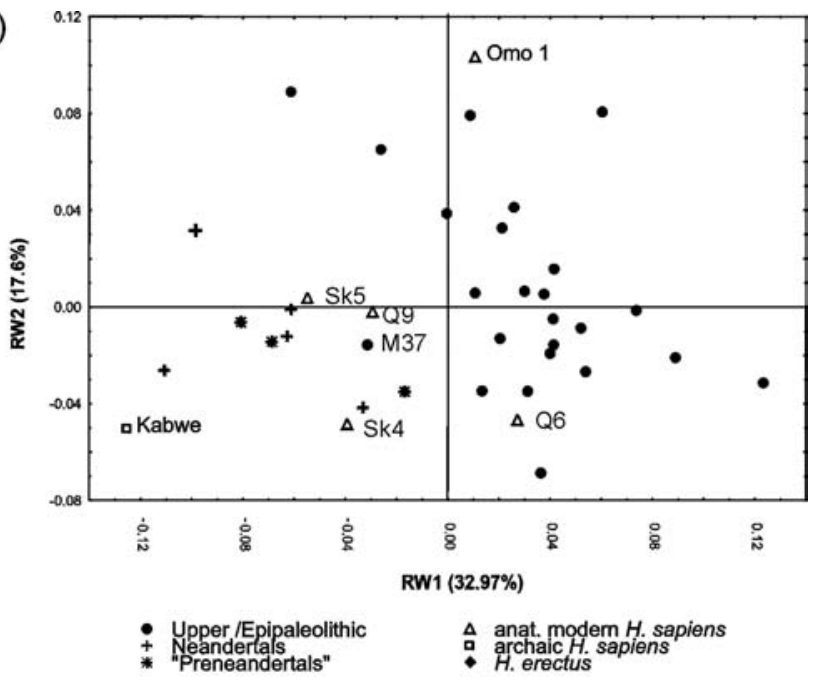

b)

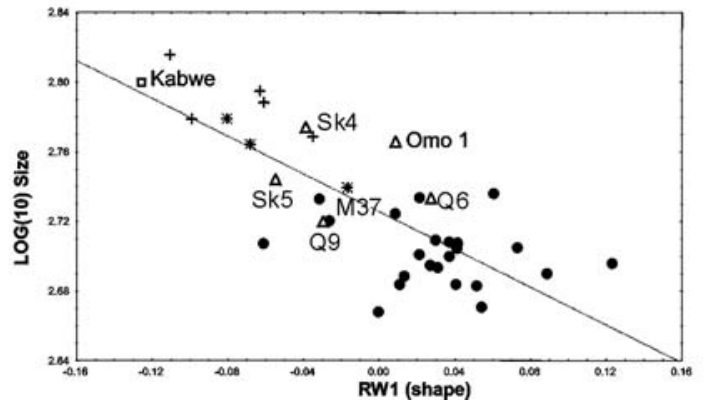

Fig. 6. Relative warps analysis of the face of Middle and Late Pleistocene hominins, M37 = Mallaha 37, Sk4 = Skhul 4, Sk5=Skhul 5, Q6 = Qafzeh 6, Q9 $=$ Qafzeh 9.. a) individual scores on relative warps 1 and 2, b) biplot of relative warp 1 against centroid size (highly significant overall allometry, $r=-0.78)$.

\section{METHODOLOGICAL ASPECTS OF LANDMARK-BASED METHODS APPLIED TO FOSSIL CRANIA}

These preliminary results need to be checked by extending the sample as well as the analysis itself to 3-dimensional comparisons. A further problem, specific to the study of the human cranium, lies in the use of landmarks for the description of shape. Booksteins recommendation to use type 1 landmarks whenever possible (or type 4 landmarks, see Bookstein, 1997), i.e., points that can be defined unambiguously and without any geometric or orientational reference, is difficult to respect while studying human crania. In fact, one needs more than points of suture intersections (type 1 landmarks), in particular because certain characters, for instance the occipital bun or the parietal flattening, are not only highly relevant from the phylogenetic point of view, but also impossible to describe with type 1 landmarks. This consideration leads to the question whether the use of type 2 and 3 landmarks alters the shape change described in this study.

In order to evaluate potential effects of deficient landmarks, different configurations of a reduced set of fossil specimens $(n=15)$ were explored using the relative warps. In total, 4 different sets with a variable proportion of the three landmark types were analyzed, adding more and more deficient landmarks to the successive configurations (for details and landmark definitions, see Frieß, 1999). The first configuration, using type 1 and 2 landmarks, covers points across the complete skull. However, the overall coverage of vault shape is rather incomplete, because the vault itself provides very few type 1 landmarks. Judging from the plot of the first two axes and the associated shape change (Fig. 7a), it is confirmed that Neandertals have a very distinct basic cranial geometry, mainly due to a vertical extension of the anterior portion relative to the posterior parts. There is also a clear flattening of the cranium in the bregma region and at lambda. In the second configuration (analysis 2), more landmarks were added, such as maximum curvature points, referred to as type 2 as well as deficient or type 3 landmarks (landmarks 5,6 and 8). As one can notice in Fig. 7b, the variation among this restricted fossil sample remains the same, with Neandertals showing very different scores in the first plane from modern humans. The thin-plate spline confirms what is found in the first configuration, i.e. a vertical extension of the face and frontal, with a clear flattening around bregma. It is evident that the newly added points supply additional information on other portions of the cranium, but the basic shape change as well as population variation remains unchanged. The third configuration is identical to the one used for the main study in this paper. It describes the cranial vault with all three landmark types, including deficient landmarks on the frontal (landmarks 2 and 3), the parietal (landmark 5) and the occipital (landmark 7). There is a persistent lambdoid flattening in Neandertals (landmark 6), as well as the general flattening of the vault, while a vertical extension is this time restricted to the supraobital region (Fig. 7c). Finally, the full cranial shape variation including the lower jaw (landmarks 16 to 19), with about half type 1 and half deficient landmarks (Fig. 7d), provides a very similar result in terms of group differences and shape change compared to analyses 1 to 3 . All analyses indicate that our subsample contains two 
major poles of cranial morphology, Neandertals on the one hand and modern humans on the other, which is only the consequence of our non random selection for this subsample. What is noteworthy here is that all four analyses reveal the same major within-sample variations, despite the fact that they are based on different landmark types and configurations.
Therefore, these comparative analyses indicate that the use of deficient landmarks in these particular configurations does not alter the results, as far as observable shape change and variations among populations are concerned. Whether the same can be said for the statistical power of these analyses remains to be tested in a differently designed study.

- Neandertals - Upper/Epipaleolithic

a)

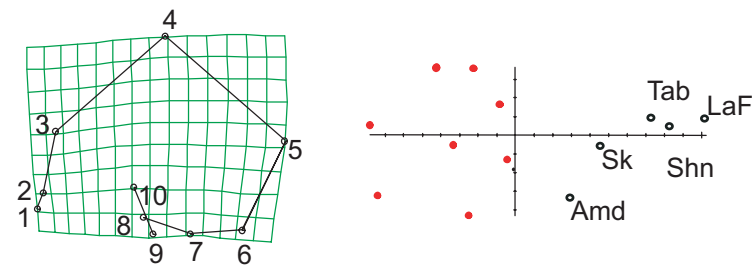

b)
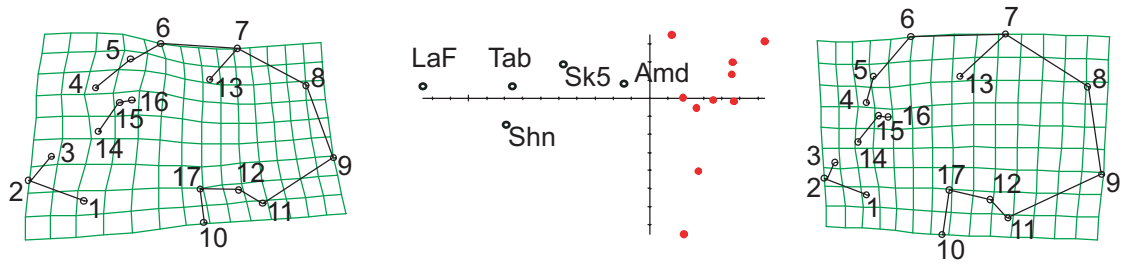

c)
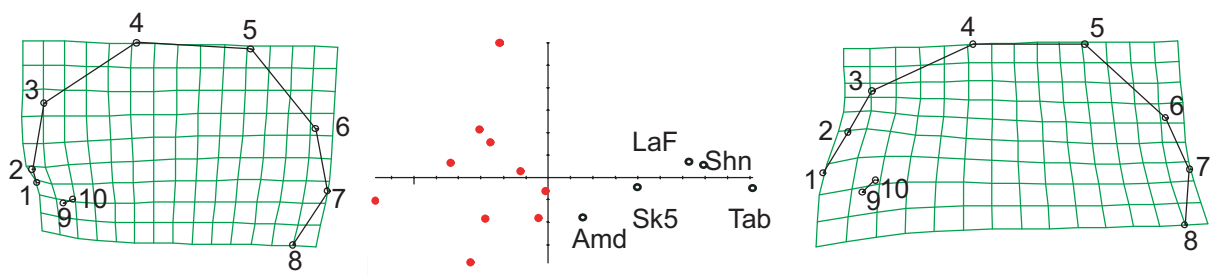

d)
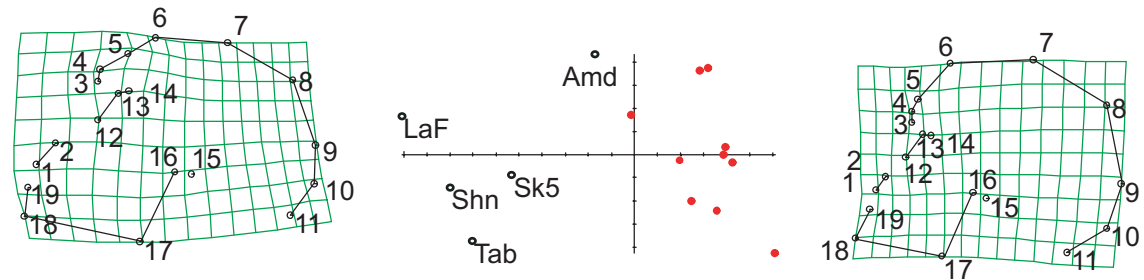

Fig. 7. Relative warps analyses with a variable number of type 1, 2 and 3 landmarks, using a restricted sample of Neandertals and Upper/Epipaleolithic modern Humans a) cranium b) portions of the vault and the face using type 1 to 3 landmarks c) cranial vault d) cranium including the lower jaw, using type 1 to 3 landmarks. 


\section{CONCLUSION}

The purpose of this paper was twofold: First, to provide new insight into the variation of craniofacial variation among later Pleistocene hominins. Second, to discuss methodological issues inherent to the use of photography on the one hand and the use of deficient landmarks on the other, both being common in paleoanthropology. As far as the phylogenetic aspects of this study are concerned, two points can be emphasized: Although the term "archaic Homo sapiens" implies a relatively close relationship to modern Homo sapiens, various fossil remains assigned to this taxon do not show any particular affinity to later anatomically modern humans. Instead, their cranial and facial shape appears closer to Neandertals, which is consistent with assigning some of them to the species Homo heidelbergensis (Rightmire, 1996; Tattersall, 1995). Very few African fossils (Omo 1, Singa) as well as the specimens from Skhul and Qafzeh in Israel possess a clearly modern cranial shape. Given their clear morphometric distance to other "archaic Homo sapiens", the concept of gradual evolution to modern humans in Africa is not supported.

The methodological aspects of this study allow us to suggest that the relative warps analysis appears to be rather robust even when geometrically dependent landmarks are used. However, this conclusion is only preliminary, since it is restricted to a very specific sample of human crania. Other biological objects may give very different results, but they may not share the crucial lack of clearly defined landmarks. Furthermore, with the recently introduced concept of sliding landmarks (Bookstein, 1997) the problem of deficient landmarks may become obsolete, once the methods are implemented in the available software. Insufficient raw data accuracy, on the other hand, appears to be a more important, yet apparently insufficiently recognized source of biased results.

\section{REFERENCES}

Bookstein FL (1991). Morphometric tools for landmark data. New York: Cambridge University Press.

Bookstein FL (1997). Landmark methods for forms without landmarks: Localizing group differences in outline shape: Medical Image Analysis 1:225-43.

Bräuer G (1984). A Craniological Approach to the Origin of Anatomically Modern Homo sapiens in Africa and Implications for the Appearance of Modern Europeans. In: Smith FH, Spencer F, eds. The Origins of Modern Humans: A world survey of the fossil evidence. New York: Allan R Liss Inc. 327-410.

Bräuer G, Yokoyama Y, Falguères C, Mbua E (1997). Modern human origins backdated: Nature 386:337.

Cann RL, Stoneking M, Wilson C (1987). Mitochondrial DNA and human evolution. Nature 325:479-99.

Chaline J (1998). Vers une approche globale de l'évolution des Hominidés. CR Acad Sci 326:307-18.

Frieß M (1997). Analyses de formes crâniennes fondées sur la photogrammétrie. Biom Hum et Anthropol 15(12):19-22.

Frieß M (1999). Taille et conformation crânienne chez les Hominidés de la fin du Pléistocène - Contributions de la morphométrie géométrique au débat sur l'origine de l'Homme moderne. BAR International Series 799:241.

Jacobshagen B, Berghaus G, Knußman R, Sperwien A, Zeltner H (1988). Fotogrammetrische Methoden. In: Knußmann R, ed. Anthropologie. Handbuch der vergleichenden Biologie des Menschen. Band I, 1. Teil. Stuttgart: Springer, 328-45.

Mann A (1995). Modern Human Origins: Evidence from the Near East. Paléorient 21(2):35-46.

Nitecki MH, Nitecki DV (1994). Origins of anatomically modern humans. New York: Plenum Press.

Rak Y (1986). The Neanderthal: A new look at an old face. J Hum Evol 15:151-64.

Rightmire GP (1996). The human cranium from Bodo: Evidence for speciation in the Middle Pleistocene? J Hum Evol 31:21-39.

Rohlf FJ, Marcus L (1993). A revolution in morphometrics. Trends Ecol Evol 8(4):129-32.

Rohlf FJ (1996). TPSdig, version 1.08. Department of Ecology and Evolution, State University of New York, Stony Brook.

Rohlf FJ (1997). TPSRelw, version 1.13. Department of Ecology and Evolution, State University of New York, Stony Brook.

Rohlf FJ (2000). Statistical power comparisons among alternative morphometric methods. Amer J Phys Anthropol. 111:463-78.

Slice DE (1994). GRF-ND, revision 11-01-94. Department of Ecology and Evolution, State University of New York, Stony Brook.

Stringer CB (1994). Out of Africa - A personal history. In: Nitecki MH, Nitecki DV, eds. Origins of anatomically modern humans. New York: Plenum Press, 149-72.

Suzuki H, Takai F (1970). The Amud man and his cave site. Tokyo: The University of Tokyo Press.

Tattersall I (1995). The last Neandertal: The rise, success, and mysterious extinction of our closest human relative. New York: MacMillan.

Thompson D'Arcy W (1917). On growth and form. London: Cambridge University Press, $753 \mathrm{pp}$.

Trinkaus E (1987). The Neandertal face: evolutionary and 
functional perspectives on a recent hominid face. $\mathrm{J}$ Hum Evol 16:429-43.

Vandermeersch B (1981). Les Hommes Fossiles de Qafzeh (Israël). Paris: Editions du CNRS.

Wolpoff M.H, Wu XZ, Thorne AG (1984). Modern Homo sapiens origins: A general theory of hominid evolution involving the fossil evidence from east Africa. In: Smith FH, Spencer F, eds. The origins of modern humans: A world survey of the fossil evidence. New York: Allan R Liss Inc., 411-83.

Wood B (1994). The problems of our origins. J Hum Evol 27:519-29.

Yaroch LA (1996). Shape analysis using the thin-plate spline: Neanderthal cranial chape as an example. Yearb Phys Anthropol 39:43-89.

\section{Softwares}

GRF-ND, revision 11-01-94: (c) DE Slice 1994. Department of Ecology and Evolution, State University of New York, Stony Brook.

TPSdig, version 1.08 : (C) FJ Rohlf 1996. Department of Ecology and Evolution, State University of New York, Stony Brook.

TPSRelw, version 1.13: (C) FJ Rohlf 1997. Department of Ecology and Evolution, State University of New York, Stony Brook. 